\title{
Construyendo memorias desde la autonomía: Lecciones del programa Jóvenes y Memoria de Buenos Aires ${ }^{1}$
}

\author{
Angie Paola Ariza \\ Master en Cultura de Paz Universidad \\ de Cádiz \\ angie.arizapo@alum.uca.es
}

\section{Resumen de la experiencia}

Desde el año 2002 los y las jóvenes de la provincia de Buenos Aires (Argentina) han sido invitados por el Programa Jóvenes y Memoria desarrollar proyectos de investigación desde la perspectiva de los derechos humanos. Las directrices de este programa, liderado por la Comisión Provincial por la Memoria, para realizar estos proyectos son sencillas y claras: (1) Que el tema abordado en los proyectos interpele directamente a su comunidad local y logre identificar acontecimientos significativos en relación con los derechos humanos, bien sea de su pasado reciente y/o de la actualidad (2) Por este motivo se impulsa a hacer trabajo de campo, por ejemplo, realizar entrevistas a diferentes agentes de la comunidad que permita conocer diferentes perspectivas sobre el tema. (3) Entablar una relación entre creacióninvestigación para que los resultados obtenidos durante cada proceso investigativo se muestren a los demás grupos de la provincia a través de una obra artística o por medio de plataformas comunicativas, como programas radiales.

Este programa es una escuela para el impulso y fortalecimiento de procesos de memoria histórica y de defensa de derechos humanos en diversas latitudes. El área de educación de la Comisión apuesta con este programa a la construcción plural y abierta de la memoria, así como "a la formación de una ética política de las nuevas generaciones basada en los derechos humanos y la solidaridad histórica con las viejas generaciones”. (Raggio;2017). En este sentido la elaboración de memorias adquiere un papel activo en la construcción de la intervención social presente en relación con los derechos humanos.

Este texto surge de una serie de etnografías realizadas en varias actividades de la etapa final de Jóvenes y Memoria en su edición 2017, un año en el que más de trece mil jóvenes y más de dos mil docentes bonarenses participaron de la propuesta y en el que la defensa de los derechos humanos en la democracia argentina ha enfrentado múltiples retos como la desaparición de Santiago Maldonado y la muerte de Rafael Nahuel. Asistimos puntualmente a tres actividades: las sesiones del trabajo de investigación de uno de los grupos de jóvenes, los encuentros de voluntarias y voluntarios que dinamizan el programa y el encuentro final

${ }^{1}$ Recibido: 19/07/2018 Evaluado: 21/08/2018 Aceptado: 22/09/2018 
de todos los grupos en donde se comparten los resultados del trabajo realizado durante el curso.

1. El trabajo de investigación realizado por los grupos de jóvenes: A comienzos de cada año, desde el año 2002, la Comisión lanza la convocatoria a grupos constituidos de manera voluntaria en las escuelas de la provincia de Buenos Aires para participar en el programa con sus proyectos de investigación. A partir del año 2007 la invitación se extiende también a grupos constituidos en asociaciones o colectivos sociales, culturales y políticos. En los inicios del programa la mayoría de los proyectos abordaban el tema de la dictadura argentina ejercida por Proceso de Reorganización Nacional; actualmente, es mayor el porcentaje de grupos que se interesan por la agenda actual de los derechos humanos, sin que esto signifique dejar de lado las memorias de la dictadura, sino que estas se ponen en diálogo con el panorama actual del país. La propuesta es que estos proyectos apunten al diálogo entre lo estructural y lo local, logren identificar perspectivas de investigación que son importantes para su comunidad y no han sido suficientemente abordadas, introduzcan matices a los debates y elaboren narrativas contra-hegemónicas. Por ejemplo, frente al discurso dicotómico amigo-enemigo que caracteriza las narrativas de la dictadura, algunos de los proyectos han reconstruido las historias de vida de militares que se resistieron al régimen o de militares-militantes que también desaparecieron por el Proceso de Reorganización Nacional.

Uno de los temas recurrentes en los proyectos de 2017 fue la violencia institucional, como la que ejercen las fuerzas policiales contra los jóvenes. Otro de los temas que con el pasar de los años adquiere fuerza es el de identidades de género. Una de las escuelas de la ciudad de la Plata se interesó por las problemáticas que abordan los y las jóvenes transgénero en la escuela. Así abrieron un espacio de escucha a las personas transgénero de su comunidad educativa e hicieron ejercicios de reconocimiento de las propias prácticas discriminatorias que han ejercido y las que ejerce su contexto social de manera sistemática. En este sentido el trabajo invita a la construcción y la expresión de opiniones sobre temas que los jóvenes no habían problematizado con anterioridad, aunque formen parte de su cotidianidad.

2. Los encuentros de los y las voluntarias del programa: El voluntariado de Jóvenes y Memoria es un espacio de formación y militancia política en derechos humanos, de carácter no partidista, que acompaña diversos escenarios del programa. Este espacio ha sido creado desde hace diez años y ha resultado fundamental en el apoyo de actividades como los encuentros regionales o el encuentro final de Chapadmalal. Los y las voluntarias en su mayoría han participado como parte de los grupos de investigación en ediciones anteriores del programa y han querido seguir participando en el mismo desde el voluntariado.

3. El encuentro final de Chapadmalal: Este encuentro es una oportunidad para que cada uno de los grupos de investigación conozca las problemáticas de otras localidades desde la perspectiva de otros jóvenes; además se piensa como un escenario en el que es posible soñar y construir colectivamente un mundo horizontal y libre de violencias, por lo menos por dos días. En el año 2017 participaron en el encuentro más de trece mil jóvenes que tenían entre manos el trabajo que habían realizado durante el año y mostraban por medio de videos, obras de teatro, murales, murgas, entre otros. Además, en este encuentro se ofrecen talleres de formación en diversos lenguajes artísticos como el mural, la fotografía y donde los jóvenes de diferentes grupos se conocen, comparten y crean juntos una obra que se muestra en la gala 
de cierre del evento. Otro de los espacios que se dan en Chapa es la radio abierta, la cual se pone a disposición ofreciendo el micrófono para quienes quieran discutir conjuntamente sobre la temática seleccionada.

La fortaleza del programa Jóvenes y Memoria reside en la autonomía que se les da a los y las jóvenes para desarrollar sus proyectos, en la cercanía que tienen con los temas que abordan y en la relación que se entabla entre investigación-creación. Además, la Comisión abre una posibilidad real para que la juventud se apropie de los espacios del programa: proponiendo talleres, metodologías de investigación y creación, temas de discusión. Esta iniciativa ha logrado que la juventud impulse y fortalezca acciones concretas en la defensa de los derechos humanos de sus territorios; además, ha promovido diálogos intergeneracionales, iniciativas de los adultos en el tema, la emergencia de nuevas perspectivas discursivas y se ha convertido en el puente hacia la participación de la juventud en otros espacios de defensa de derechos y hacia la apertura de la escuela a otros actores comunitarios. Es este un ejemplo de concepción de la memoria histórica como fundamento hacia la imaginación y construcción ciudadana activa de otros futuros posibles que partan desde el reconocimiento de la diversidad de violencias estructurales que han construido nuestro presente.

\section{Referencias}

Raggio, S (2017) En Memorias del foro internacional sobre pedagogía, memoria y violencia. Medellín: La Carreta Ed 